\title{
Marketing post-pandemia
}

\section{Post-pandemic marketing}

Omar Cruz-Gómez ${ }^{a}$, Ana Yuridia Morales-Flores ${ }^{b}$

\begin{abstract}
:
Due to the COVID-19 pandemic. The sales or purchases of products and services took a worldwide round turn. Unfortunately, many SMEs were forced to close permanently. And those who were able to return, had to adapt to a new normal in order to avoid common habits such as physical contact, at all costs. For this reason, they had to create new sales strategies in order to reach the final customer. And a wave of digital marketing grew, which have already existed, but now with greater seriousness and commitment to users.
\end{abstract}

Keywords:

Digital marketing, Covid-19, websites, digital platforms.

Resumen:

Debido a la pandemia ocasionada por el COVID-19. La compra-venta de productos o servicios a nivel mundial dio un rotundo giro que $360^{\circ}$, tristemente muchos negocios se vieron obligados a cerrar de forma permanente. Y los que pudieron regresar, tuvieron que adaptarse a una nueva normalidad que evitaba a toda costa hábitos comunes, como el contacto físico. Por ello, tuvieron que crear nuevas estrategias de ventas para poder llegar al cliente final, y creció la ola de marketing digital, mismo que ya existía, pero ahora con mayor seriedad y compromiso con los usuarios.

Palabras Clave:

Marketing digital, Covid-19, sitios web, plataformas digitales.

\section{Introducción}

Modificar estrategias de marketing, apostar por plataformas digitales nuevas o ya existentes, así como, redefinir el propósito sin cambiar el objetivo final, que es el cliente. Son algunas de los cambios radicales que tuvieron que hacer todos los negocios desde las pymes hasta las más grandes organizaciones durante la pandemia (López, 2020).

Antes del giro $360^{\circ}$ que dio la vida cotidiana a principios del 2020, el marketing digital era muy poco utilizado, las empresas y negocios enfocaban la venta de sus productos a través del contacto directo. Si ponemos ejemplos de ello; Hershey's, Coca Cola y Bimbo, promovían las relaciones afectivas, como abrazos y contacto físico para elevar sus ventas. Por lo que tuvieron que reinventarse (López, 2020).
Y qué decir de los pequeños y medianos negocios que se vieron obligados a cerrar temporalmente para salvaguardar la salud de sus trabajadores, volviendo solo algunos, a laborar, con nuevas normas, protegiendo así a todas las familias que dependían de ello.

\section{Un plan que llevaría años de evolución digital, la pandemia lo aceleró escasos meses}

\begin{abstract}
Empecemos por el uso de las redes sociales, anteriormente, se solía darle poca seriedad a la venta de productos por internet, por lo que algunos sitios desarrollaron algoritmos para que los usuarios tuvieran mayor seguridad en el uso de sus datos. Pero de poco sirvió, debido a que el cliente prefería pagar más, acudiendo a las instalaciones que por un servicio a domicilio (Cavezzali, 2020).
\end{abstract}

\footnotetext{
a Universidad Autónoma del Estado de Hidalgo, Email: ocruzg@uaeh.edu.mx

b Autor de Correspondencia, Universidad Autónoma del Estado de Hidalgo, Email: ana_morales9717@uaeh.edu.mx
} 
Posterior a la pandemia, el cliente se vio en la necesidad de esperar y confiar en el marketing digital para poder adquirir los productos necesarios o de su preferencia.

Permitiendo así a las pymes, y grandes empresas usar el data del cliente, para mejorar los servicios (Escamilla, 2020).

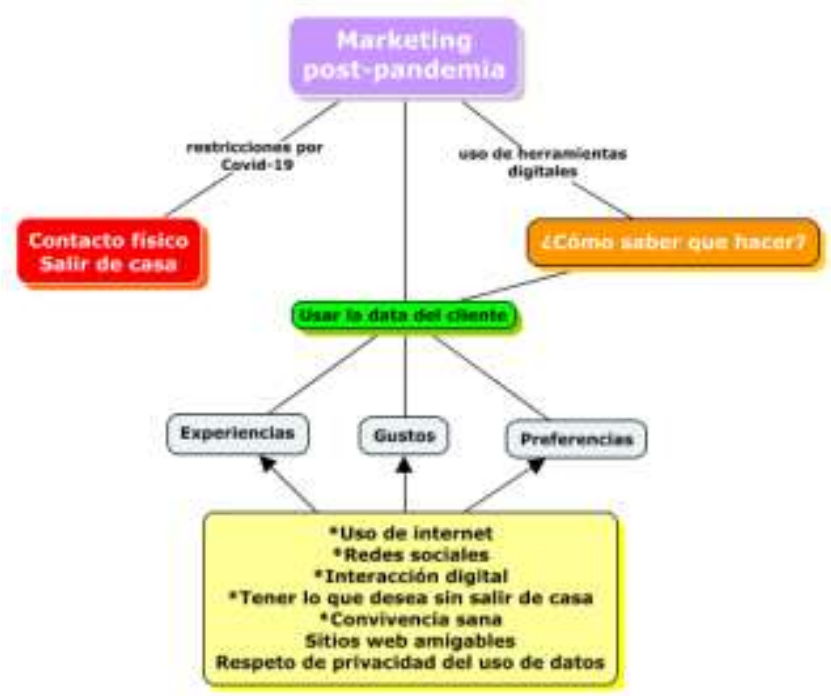

Figure 1. Antes de la pandemia

Hoy en día, es más fácil para el usuario final hacer compras en línea, y los sitios web mejoraron la seguridad del uso de datos para ganar mayor confianza.

\section{Finalmente, nos adaptamos.}

Es así como nos encontramos ahora, ocupando plataformas que nos negábamos a utilizar. Las redes sociales pasaron de ser personales a espacios para promover productos o servicios. Así como también, creció el uso de las páginas web para darle mayor seriedad y seguridad al cliente, al momento de comprar.

Desconocemos si la vida volverá a la normalidad pronto, o si será igual que antes del COVID-19 (Cabrera, 2020). Lo que, sí podemos asegurar, es que las nuevas tecnologías y el uso de herramientas digitales, se quedarán por un largo tiempo o quizás ya sean parte de la nueva normalidad cuando el mundo esté finalmente en semáforo verde.

\section{Referencias}

[1] Cabrera, R. (23 de Junio de 2020). Funnel MKT expert. Obtenido de La importancia de un sitio web en época de pandemia: https://funnel.mx/blog/importancia-de-un-sitio-web-en-la-pandemia/.

[2] Cavezzali, C. (14 de Diciembre de 2020). Puro marketing. Obtenido de La revolución del marketing digital post pandemia: https://www.puromarketing.com/30/34624/revolucionmarketing-digital-post-pandemia.html.
[3] Escamilla, O. (21 de 01 de 2020). Merca 2.0. Obtenido de Formas de usar la data del consumidor para mejorar su experiencia con la marca: https://www.merca20.com/formas-de-usar-la-data-delconsumidor-para-mejorar-su-experiencia-con-la-marca/.

[4] López, Z. (26 de Agosto de 2020). Expansión. Obtenido de https://expansion.mx/mercadotecnia/2020/08/26/hersheys-donjulio-y-bimbo-estrategias-de-marketing-que-el-covid-19cambio. 